\title{
Microbial Risk Factors of Cardiovascular and Cerebrovascular Diseases: Potential Therapeutical Options
}

\author{
Mohammed Abdalla Abbas ${ }^{\mathrm{a}, \mathrm{b}}$, Albrecht Guenther ${ }^{\mathrm{c}}$, Sebastiano Galantucci ${ }^{\mathrm{a}}$, Gharib Fawi ${ }^{\mathrm{a}}$, Giancarlo \\ Comi $^{\mathrm{b}}$, Joseph Kwan $^{\mathrm{d}}$ and Francesco Corea*,
}

${ }^{a}$ Neurology Department, Sohag Faculty of Medicine, Sohag University, Sohag, Egypt
${ }^{b}$ Istituto di Neurologia Sperimentale (INSPE), Istituto di Ricovero e Cura a Carattere Scientifico (IRCCS) San Raffaele,
Milano, Neurologia, Dimer, Via Olgettina, 48, 20132, Milano, Italy
${ }^{c}$ Department of Neurology, Friedrich-Schiller-University, Jena, Erlanger Allee 101, 07747 Jena, Germany
${ }^{d}$ Department of Medicine for the Elderly, Royal Bournemouth Hospital, Castle Lane East, Bournemouth, BH7 7DW, UK

Abstract: Infection and inflammation may have a crucial role in the pathogenesis of atherosclerosis. This hypothesis is supported by an increasing number of reports on the interaction between chronic infection, inflammation, and atherogenesis. Assessment of serological and inflammatory markers of infection may be useful adjuncts in identifying those patients who are at a higher risk of developing vascular events, and in whom more aggressive treatments might be warranted.

Keywords: Stroke, risk factors, infection, Helicobacter pylori, Chlamydia pneumoniae, Cytomegalovirus, odontopathogens, atherosclerosis, therapy, antibiotics.

\section{INTRODUCTION}

Cerebrovascular disease (CVD) is the most common life threatening neurological condition, and is a major contributor to morbidity, functional disability and mortality worldwide. Recent advances in the treatment of acute ischemic stroke offer hope in reducing its devastating effects, but these therapies are only offered to a small fraction of stroke patients. Hence, effective prevention of recurrence, mortality and disability after the initial stroke is especially important [1]. The recognition of the role of inflammation in the pathogenesis, progression and clinical manifestation of atherosclerosis has resulted in a new generation of vascular research. Indeed, the first cell types to be found within the arterial intima in early atherosclerotic lesions are lymphoid cells, macrophages and smooth muscle cells [2,3]. Infections with organisms such as Helicobacter pylori (HP), Chlamydia pneumoniae (CP), Cytomegalovirus (CMV) and odontopathogens, are potentially treatable emerging atherosclerotic risk factors [4]. An increasing number of seroepidemiological, pathological, immunological and pharmacotherapeutic studies suggest a possible link between these organisms and atherosclerosis, arterial thrombosis and plaque instability.

\section{HELICOBACTER PYLORI}

HP is a gram-negative organism that causes chronic active gastric inflammation, which is probably life-long unless eradicated by antibiotics. HP has been found to be associated

*Address correspondence to this author at the Istituto di Neurologia Sperimentale (INSPE), Istituto di Ricovero e Cura a Carattere Scientifico (IRCCS) San Raffaele, Milano, Neurologia, Dimer, Via Olgettina, 48, 20132, Milano, Italy; E-mail: corea.francesco@ hsr.it with extra-digestive diseases, in particular, vascular disorders (e.g. ischemic heart disease, primary Raynaud's phenomenon, ischemic stroke) and autoimmune disorders (e.g. Henoch-Schönlein purpura, Sjögren's syndrome). Many case-control studies have reported a significant association between HP seropositivity and coronary heart disease (CHD) and ischemic electrocardiographic changes, independent of conventional risk factors and socioeconomic factors $[5,6]$.

\section{Possible Pathological Mechanisms}

- $\quad$ Chronic HP infection can cause a low grade chronic inflammatory response, as indicated by raised serological markers including fibrinogen, leukocyte count, and C-reactive protein (CRP) [5].

- $\quad$ Free radical formation may be important as levels of antioxidants have been shown to be decreased in subjects with HP infection [7]; this could result in lipid peroxidation.

- HP infection produces $60 \mathrm{kDa}$ heat shock proteins, which have a high degree of sequence homology with human $60 \mathrm{kDa}$ heat shock proteins; presence of crossreacting antibodies to heat shock proteins have been shown to be a risk factor for carotid atherosclerosis [8].

- $\quad$ Platelet activation and aggregation have been detected in patients infected with HP [9].

- Hyperhomocysteinemia may possibly be indirectly related to HP infection because chronic gastritis caused by HP infection can lead to vitamin and folate deficiency, which in turn result in problems with methylation by 5-methyl-tetrahydrofolic acid and an accumulation of homocysteine in susceptible patients 
[10]. Homocysteine is toxic to endothelial cells and results in vascular lesions and ischemic insults.

\section{CHLAMYDIA PNEUMONIAE}

$\mathrm{CP}$ is an intracellular gram-negative bacterium that commonly causes respiratory infections in all age groups. Humoral antibodies against $\mathrm{CP}$ have been found in more than half of the adult population [11]. IgA antibody may be a more reliable than IgG as a marker for chronic chlamydial infection [11]. A number of cross-sectional and prospective studies have demonstrated an association between high levels of antibody against CP and CHD [12]. Results from many other studies also suggest a role for CP in carotid artery thrombosis [13] and CVD [14-19].

\section{Possible Pathological Mechanisms}

\section{Local Effects}

CP has been proposed to affect and contribute to the mechanisms involved in atherosclerotic disease process. As a prerequisite, the pathogenic organism must gain entry into the cells of the arterial wall. It is hypothesized that CP may be phagocytosed by alveolar macrophages in the lung and transported by the blood to the subendothelial region through the injured arterial endothelium [20]. Macrophages infected with CP may promote the inflammatory process of atherosclerosis by inducing the production of cytokines and lipoproteins[20], and degenerating into foam cells . CP DNA has been detected in atherosclerotic tissues at different sites of the vascular system.

\section{Systemic Effects}

- $\quad \mathrm{CP}$ can induce an inflammatory response, as indicated by raised CRP, leukocyte count, IL-6, IL-8, tumour necrosis factor $\alpha(\mathrm{TNF} \alpha)$, and expression of tissue factor (factor VIIa antigen) [21,22].

- $\quad \mathrm{CP}$ can secrete endotoxin and cause activation of monocytes, monocyte integrins and monocytederived macrophages $[23,24]$.

- $\quad \mathrm{CP}$ infection can activate the nuclear factor for the expression of immunoglobulin $\kappa$ light chain in the Blymphocytes pathway (nuclear factor-kappa B) ${ }^{44}$.

- $\quad$ There may be immunological reaction against myosin filaments of carotid artery wall smooth muscle cells due to antigenic mimicry between heavy chains of myosin filaments and specific antigens $(40,42,52$, $54,60,75,98 \mathrm{kDa}$ ) presented on CP outer membrane [25].

- Antibodies to chlamydial HSP 60 can cause endothelial cytotoxicity [24]. There is also an antigenic mimicry between human and chlamydial HSP 65; one prospective population-based study strongly supports a potential atherogenic role of persistent $\mathrm{CP}$ infection due to immune reactions to HSP 65 [26].

- $\quad$ CP seropositivity can be associated with endothelial dysfunction [27], as indicated by elevated levels of soluble endothelial cell adhesion molecules (sCAMs) as markers of atherosclerotic activity [28].

- $\quad$ CP lipopolysaccharides have been found in circulating immune complexes observed in chronically in- fected patients [14]. These lipopolysaccharides may have deleterious effects on the coagulation system and vascular endothelium.

- $\quad$ Persistent CP infection may be associated with increased fibrinogen [29], platelet accumulation and adhesion [30], thrombin [31], plasminogen activator inhibitor [22], and enhanced activity of hemostatic and pro-coagulant mediators [30].

- $\quad \mathrm{CP}$ infection can cause alteration of cholesterol metabolism and lipid oxidation [23], increased triglycerides [32], increased lipoprotein (a) levels [29], increased total cholesterol levels [33], and decreased high-density lipoprotein cholesterol levels [32,33].

\section{CYTOMEGALOVIRUS}

CMV, or Human Herpes Virus 5, is a double-stranded enveloped DNA virus of the Herpesviridae family. The diagnosis of acute CMV infection is usually based on serology. Newer methods of diagnosis include the presence of pp65 antigen in granulocytes from peripheral blood, viral DNA detection by PCR, viral mRNA detection by nucleic acid sequence-based amplification, conventional cell culture, or detection of early antigen fluorescent foci in cultures [34].

The involvement CMV in some cardiovascular conditions is well known. CMV may also be involved in the pathogenesis of vasculitis, and when this occurs within the central nervous system, it can lead to cerebral infarction $[35,36]$. There is a growing body of knowledge supporting the hypothesis that CMV may be involved in the development of atherosclerosis [37-40]. Several cross-sectional and prospective studies have indicated that high titres of antibodies to CMV may be associated with CHD [12]. High antiCMV antibody titre not only appears to be associated with active CHD, but also an early predictor of atherosclerosis [41]. Indeed, CMV infection increases the risk of coronary artery restenosis after angioplasty, stent placement or bypass, and accelerates cardiac transplant-associated coronary atherosclerosis [42]. On the other hand, results from a number of in vivo and in vitro studies may not support this hypothesis [43-47]. CMV infections have also been found to significantly influence the occurrence of cerebrovascular events in patients with baseline asymptomatic carotid lesions [48], or those with diabetes [49].

\section{Possible Pathological Mechanisms}

- $\quad$ CMV can cause local inflammation, as indicated by the presence of CMV DNA in atheromatous plaques $^{41}$. Vessel wall colonization by CMV may result in cytokine induction or antigen stimulation.

- CMV infection can be associated with thrombocytopenia, thrombotic thrombocytopenic purpura [50], and acute arterial and venous thromboembolism [51, 52].

- CMV seropositivity can be associated with endothelial dysfunction and impaired responses to nitric oxide independently of conventional risk factors [53].

- Chemokine production and expression of virally encoded chemokine receptors have been demonstrated in infected smooth muscle cells (SMC), this can lead to proliferation and/or migration of SMC from the 
vessel media to the intima, and culminate in vessel narrowing [54].

- $\quad$ Further immunological mechanisms may play a role as indicated by a recent study [2] which revealed that, during CMV infection, a subset of antibodies directed against particular viral proteins cross-reacted with normally expressed cell-surface molecules, causing apoptotic cell death of non-stressed endothelial cells through a mechanism of molecular mimicry. Moreover, in atherosclerosis, the stress induced in endothelial cells by the CMV infection (or reactivation from latency) can lead to the expression of HSP 60. Crossreactive anti-CMV antibodies may also amplify the endothelial damage by binding surface HSP 60 and inducing cytotoxicity.

\section{ODONTOPATHOGENS}

Periodontitis is a chronic infection by oral bacteria that affect the supporting structures of the teeth. Bacterial populations attached to dental surface consist of biofilm communities, sometimes 50-100 cells in thickness and with a bacterial density of up to $10^{11}$ Colony Forming Units/mg, forming a very complex ecosystem. This is due, in part, to the nonshedding surface of the teeth, which allows the development of persistent colonization.

During the past two decades, there has been an increasing interest in the impact of oral health on atherosclerosis and subsequent CVD. Exposure to periodontal infection might influence the development of coronary [55], carotid and peripheral vascular disease [56]. Porphyromonas gingivalis and Streptococcus sanguis are major pathogens associated with periodontitis, and research has shown that these infectious agents may influence vascular cell functions by inducing thrombus formation, vascular cell proliferation, apoptosis, and cell death. A mild to moderate association between periodontitis and the development of CHD and ischemic CVD has been observed [57]. One meta-analysis of prospective and retrospective follow-up studies also concluded that periodontal disease may increase the risk of cardiovascular disease by approximately $20 \%$, and the risk of CVD by almost two-fold [57, 58].

\section{Possible Pathological Mechanisms}

- Gram-negative bacterial infection causes an endotoxemia. Research so far suggests that neopterin, which reflects immune activation of monocytes and macrophages, functions as atherogenic effect modifying factor on the effects of endotoxin [59]. It is hypothesized that immune activation via induction of endotoxin hyper-responsiveness determines the atherogenic potential of periodontal infections [59].

- Before periodontal treatments, individuals with periodontitis have been found to have higher concentrations of total and low-density lipoprotein cholesterol and triglycerides, and lower concentrations of highdensity lipoprotein cholesterol [60].

- $\quad$ Periodontitis can induce a peripheral inflammatory and immune response, as evidenced by elevated concentrations of CRP and IgA antibodies to periodontal pathogens. The prevalence of CVD appears to be highest in patients with periodontitis and co-existing elevated CRP levels, suggesting that periodontitis might increase the risk of vascular disease through activating the systemic inflammatory and immune responses. There may also be a genetic component which has as yet not been elucidated.

- Porphyromonas gingivitis can cause aggregation of human platelets in platelet-rich plasma [61].

\section{POTENTIAL THERAPEUTIC OPTIONS}

There is now some evidence that the microbial risk factors for vascular disease might be treatable. Several preliminary interventional studies have found that antibiotic therapy might improve the prognosis for patients with coronary heart disease $[62,63]$. Infection of vascular endothelial cells with $\mathrm{CP}$ increases the expression of pro-atherogenic cytokines mediated by the transcription factor nuclear factor (NF)kappaB, and NF-kappaB-mediated gene activation represents a crucial step in the developmental cycle of CP. One possible reason why aspirin is cardio-protective may be that it can exert an anti-chlamydial effect from inhibiting CP-induced NF-kappaB activation [64]. Macrolides, which are effective against Chlamydia pneumoniae, may also have several nonantibiotic (mostly anti-inflammatory) effects which can contribute towards preventing cardio- and cerebrovascular diseases (see Table 1) [65]. One study found that certain macrolides (roxithromycin and azithromycin) can significantly reduce the levels of IL-8 and monocyte chemotactic protein (MCP)-1, which in turn may inhibit trans-endothelial migration (TEM) of neutrophils and monocytes [66]. In another prospective study, patients receiving roxithromycin were significantly less likely to suffer an acute coronary event at 30 days [67]. Fong et al. [68] showed that clarithromycin administration may modify atherosclerotic lesions by reducing the likelihood of detecting CP bacteria within the lesions. Another crucial development is the emergent role of vaccination in preventing vascular diseases. Observational studies have found that vaccination against influenza may be associated with a reduced risk of stroke, myocardial infarction, and all-cause mortality [69]. Infectious diseases during childhood, even those occurring within the first year or two of life, may predispose an individual to CHD [70].

Table 1. Non-Antibiotic Effects of Macrolides

\begin{tabular}{|l|}
\hline Improved endothelial function (azithromycin) \\
\hline Antioxidant effects (erythromycin, roxithromycin) \\
\hline Decreased von Willebrand factor levels (azithromycin) \\
\hline $\begin{array}{l}\text { Decreased IL 1, } 6 \text { and } 8 \text { (azithromycin, clarithromycin, erythromycin, } \\
\text { roxithromycin) }\end{array}$ \\
\hline $\begin{array}{l}\text { Decreased TNF } \alpha \text { (azithromycin, clarithromycin, erythromycin, } \\
\text { roxithromycin) }\end{array}$ \\
\hline $\begin{array}{l}\text { Decreased granulocyte/monocyte colony-stimulating factor (clarithromy- } \\
\text { cin) }\end{array}$ \\
\hline Decreased monocyte chemotactic protein 1 (azithromycin) \\
\hline Decreased E-selectin (azithromycin) \\
\hline Decreased CRP (roxithromycin) \\
\hline
\end{tabular}




\section{CONCLUSION}

Infection and inflammation may have a crucial role in the pathogenesis of atherosclerosis. Serum markers of HP, CP, CMV and odontopathogens may predict the risk of CVD even after adjusting of traditional risk factors and socioeconomic status [71]. In the future, assessment of serological and inflammatory markers of infection may become useful adjuncts in identifying those patients who are at a higher risk of developing vascular events, and in whom more aggressive treatments might be warranted. However, the effects and cost implications of this treatment strategy are largely unknown. Vaccination before the initial exposure might be a more logical approach, and one such vaccine is currently being evaluated for CP [72]. Despite a lack of trial evidence, it is recommendable that patients with a previous stroke or at high risk of stroke should receive an annual influenza vaccination. Currently, there is insufficient evidence to recommend the routine administration of antibiotics in preventing cardio- and cerebrovascular diseases in daily clinical practice.

\section{ACKNOWLEDGMENT}

Abbas MA is spending, in Unità di Neurologia IRCCS San Raffaele, Milano-Italy, a 2 year research fellowship and basic research on microbial risk factors for cerebrovascular diseases, under the patronage of the Ministry of Higher Education, Egypt.

\section{REFERENCES}

[1] Joseph LN, Babikian VL, Allen NC, Winter MR. Risk factor modification in stroke prevention: the experience of a stroke clinic. Stroke 1999; 30: 16-20.

[2] Lunardi C, Bason C, Corrocher R, Puccetti A. Induction of endothelial cell damage by hCMV molecular mimicry. TRENDS Immunol 2005; 26: 19-24.

[3] Abbas M, Bignamini V, Corea F. Effects of chronic microbial infection on atherosclerosis. Atherosclerosis 2006; 187: 439-40.

[4] Abbas M, Sessa M, Corea F. Asymptomatic carotid lesions: traditional vs. emerging risk factors. Arch Med Res 2006; 37: 687-8.

[5] Patel P, Mendall MA, Carrington D, et al. Association of Helicobacter pylori and Chlamydia pneumoniae infections with coronary heart disease and cardiovascular risk factors. BMJ 1995; 311: 711714.

[6] Martin-de-Argila C, Boixeda D, Canton R, Gisbert JP, Fuertes A. High seroprevalence of Helicobacter pylori infection in coronary heart disease. Lancet 1995; 346: 310

[7] Phull PS, Gower JD, Price AB, Green CJ, Jacyna MR. Alphatocopherol antioxidant levels in chronic gastritis: correlation with mucosal neutrophil infiltration. Gut 1993; 34(suppl 1): T133.

[8] Xu Q, Willeit J, Marosi M, et al. Association of serum antibodies to heat-shock protein 65 with carotid atherosclerosis. Lancet 1993; 341: 255-259.

[9] Elizalde JI, Gomez J, Panes J, et al. Platelet activation In mice and human Helicobacter pylori infection. J Clin Invest 1997; 100(5): 996-1005.

[10] Kutluana U, Simsek I, Akarsu M, Kupelioglu A, Karasu S, Altekin E. Is there a possible relation between atrophic gastritis and premature atherosclerosis? Helicobacter 2005; 10(6): 623-9.

[11] Ward ME. The immunobiology and immunopathology of chlamydial infections. APMIS 1995; 103: 769-796.

[12] Fagerberg B, Gnarpe J, Gnarpe H, Agewall S, Wikstrand J. Chlamydia pneumoniae but not cytomegalovirus antibodies are associated with future risk of stroke and cardiovascular disease: a prospective study in middle-aged to elderly men with treated hypertension. Stroke 1999; 30: 299-305.

[13] Melnick SL, Shahar E, Folsom AR, et al. Past infection by Chlamydia pneumoniae strain TWAR and asymptomatic carotid atherosclerosis. Atherosclerosis Risk in Communities (ARIC) Study Investigators. Am J Med 1993; 95: 499-504.
[14] Linnanmäki E, Leinonen M, Mattila K, Neiminen MS, Valtonen V, Saikku P. Chlamydia pneumoniae-specific circulating immune complexes in patients with chronic coronary heart disease. Circulation 1993; 87: 1130-1134.

[15] Wimmer MLJ, Sandmann-Strupp R, Saikku P, Haberl RL. Association of chlamydial infection with cerebrovascular disease. Stroke 1996; 27: 2207-2210.

[16] Chiu B, Viira E, Tucker W, Fong IW. Chlamydia pneumoniae, cytomegalovirus, and herpes simplex virus in atherosclerosis of the carotid artery. Circulation 1997; 96: 2144-2148.

[17] Juvonen J, Juvonen T, Laurila A, et al. Demonstration of Chlamydia pneumoniae in the walls of abdominal aneurysms. J Vasc Surg 1997; 25: 499-505.

[18] Cook PJ, Honeybourne D, Lip GYH, Beevers DG, Wise R, Davies P. Chlamydia pneumoniae antibody titers are significantly associated with acute stroke and transient cerebral ischemia: the West Birmingham Stroke Project. Stroke 1998; 29: 404-410.

[19] Abbas MA, Corea F. Surrogate sonographic markers of atherosclerosis. Stroke 2006; 37: 1644

[20] Yamashita K, Ouch K, Shirai M, Gondo T, Nakazawa T, Ito H. Distribution of Chlamydia pneumoniae infection in the atherosclerotic artery. Stroke 1998; 29: 773-778.

[21] Anderson JL, Carlquist JF, Muhlestein JB, Horne BD, Elmer SP. Evaluation of C-reactive protein, an inflammatory marker, and infectious serology as risk factors for coronary artery disease and myocardial infarction. J Am Coll Cardiol 1998; 32: 35-41.

[22] Dechend R, Maass M, Gieffers J, et al. Chlamydia pneumoniae infection of vascular smooth muscle and endothelial cells activates NF-kappaB and induces tissue factor and PAI-1 expression: a potential link to accelerated arteriosclerosis. Circulation 1999; 100: 1369-73.

[23] Kalayoglu MV, Indrawati Morrison RP, Morrison SG, Yuan Y, Byrne GI. Chlamydial virulence determinants in atherogenesis: the role of chlamydial lipopolysaccharide and heat shock protein 60 in macrophage-lipoprotein interactions. J Infect Dis 2000; 181 (suppl 3): S483-S489.

[24] Kol A, Lichtman AH, Finberg RW, Libby P, Kurt-Jones EA. Cutting edge: heat shock protein (HSP) 60 activates the innate immune response: CD14 is an essential receptor for HSP60 activation of mononuclear cells. J Immunol 2000; 164: 13-17.

[25] Maass M, Gieffers J. Cardiovascular disease risk from prior Chlamydia pneumoniae infection can be related to certain antigens recognized in the immunoblot profile. J Infect 1997; 35: 171-176.

[26] Mayr M, Kiechl S, Willeit J, Wick G, Xu Q. Infections, immunity, and atherosclerosis: associations of antibodies to Chlamydia pneumoniae, Helicobacter pylori, and cytomegalovirus with immune reactions to heat-shock protein 60 and carotid or femoral atherosclerosis. Circulation 2000; 102: 833-839.

[27] Prasad A, Zhu J, Halcox JP, Waclawiw MA, Epstein SE, Quyyumi AA. Predisposition to atherosclerosis by infections: role of endothelial dysfunction. Circulation 2002; 106: 184-190.

[28] Schumacher A, Seljeflot I, Lerkerod AB, Sommervoll L, Otterstad JE, Arnesen H. Does infection with Chlamydia pneumoniae and/or Helicobacter pylori increase the expression of endothelial cell adhesion molecules in humans?. Clin Microbiol Infect 2002; 8(10): 654-61.

[29] Tutuncu NB, Guvener N, Tutuncu T, et al. Chlamydia pneumonia seropositivity correlates with serum fibrinogen and lipoprotein a levels: any role in atherosclerosis? Endocr J 2001; 48: 269-274.

[30] Fryer RH, Schwobe EP, Woods ML, Rodgers GM. Chlamydia species infect human vascular endothelial cells and induce procoagulant activity. J Invest Med 1997; 45: 168-174.

[31] Valtonen VV. Infection as a risk factor for infarction and atherosclerosis. Ann Med 1991; 23: 539-543.

[32] Laurila AL, Bloigu A, Nayha S, Hassi J, Leinonen M, Saikku P. Chlamydia pneumoniae antibodies associated with altered serum lipid profile. Int J Circumpolar Health 1998; 57(suppl 1): 329-332.

[33] Murray LJ, O'Reilly DP, Ong GM, O'Neill C, Evans AE, Bamford KB. Chlamydia pneumoniae antibodies are associated with an atherogenic lipid profile. Heart 1999; 81: 239-244.

[34] Chou S. Newer methods for diagnosis of cytomegalovirus. Rev Infect Dis 1990; 12(Suppl 7): S727-36.

[35] Koeppen AH, Lansing LS, Peng SK, Smith RS. Central nervous system vasculitis in cytomegalovirus infection. J Neurol Sci 1981; 51: $395-410$. 
[36] Booss J, Dann PR, Winkler SR, Griffith, BP, Kim JH. Mechanisms of injury to the central nervous system following experimental cytomegalovirus infection. Am J Otolaryngol 1990; 11: 313-7.

[37] Muhlestein, JB, Horne BD, Carlquist JF, et al. Cytomegalovirus seropositivity and C-reactive protein have independent and combined predictive value for mortality in patients with angiographically demonstrated coronary artery disease. Circulation 2000; 102: 1917-1923.

[38] Zhu J, Quyyumi AA, Norman JE, Costello R, Csako G, Epstein SE. Effects of total pathogen burden on coronary artery disease risk and C-reactive protein levels. Am J Cardiol 2000; 85: 140-146.

[39] Blankenberg S, Rupprecht HJ, Bickel C, et al. Cytomegalovirus infection with interleukin- 6 response predicts cardiac mortality in patients with coronary artery disease. Circulation 2001; 103: 29152921.

[40] Horvath R. The possible role of human cytomegalovirus (HCMV) in the origin of atherosclerosis. J Clin Virol 2000; 16: 17-24.

[41] Blum A, Peleg A, Weinberg M. Anti-cytomegalovirus (CMV) IgG antibody titer in patients with risk factors to atherosclerosis. Clin Exp Med 2003; 3(3): 157-160.

[42] Fateh-Moghadam, S. Bocksch W, Wessely R, Jager G, Hetzer R, Gawaz M. Cytomegalovirus infection status predicts progression of heart-transplant vasculopathy. Transplantation 2003; 76: 14701474.

[43] Adler SP, Hur JK, Wang JB, Vetrovec GW. Prior infection with cytomegalovirus is not a major risk factor for angiographically demonstrated coronary artery atherosclerosis. J Infect Dis 1998; 177: 209-212.

[44] Sorlie PD, Baer JT, Du Laney TV, et al. Nuclear factor-kappaB activation in endothelium by Chlamydia pneumoniae without active infection. J Infect Dis. 2003 Oct 15; 188(8): 1094-7.

[45] Nieto FJ, Adam E, Folsom AR, Shahar E, Massing M. A prospective study of cytomegalovirus, herpes simplex virus 1 , and coronary heart disease: the atherosclerosis risk in communities (ARIC) study. Arch Intern Med 2000; 160: 2027-32.

[46] Sambiase NV, Higuchi ML, Nuovo G, et al. CMV and transplantrelated coronary atherosclerosis: an immunohistochemical, in situ hybridization, and polymerase chain reaction in situ study. Mod Pathol 2000; 13: 173-9.

[47] Grahame-Clarke C, Chan NN, Andrew D, et al. Human cytomegalovirus seropositivity is associated with impaired vascular function. Circulation 2003; 108: 678-83.

[48] Rott D, Zhu J, Zhou YF, Burnett MS, Zalles-Ganley A, Epstein SE. IL-6 is produced by splenocytes derived from CMV-infected mice in response to CMV antigens, and induces MCP-1 production by endothelial cells: a new mechanistic paradigm for infectioninduced atherogenesis. Atherosclerosis 2003; 170: 223-8.

[49] Corrado E, Rizzo M, Tantillo R, et al. Markers of inflammation and infection influence the outcome of patients with baseline asymptomatic carotid lesions: a 5-year follow-up study. Stroke 2006; 37: 482-6.

[50] Guech-Ongey M, Brenner H, Twardella D, Hahmann H, Rothenbacher D. Role of cytomegalovirus sero-status in the development of secondary cardiovascular events in patients with coronary heart disease under special consideration of diabetes. Int J Cardiol 2006; 111: 98-103.

[51] Neau D, Bonnet F, Viallard JF, Longy-Boursier M, Le Bras M. Thrombotic thrombocytopenic purpura and cytomegalovirus infection in an immunocompetent adult. Clin Infect Dis 1997; 25: 14956.

[52] Abgueguen P, Delbos V, Chennebault JM, Payan C, Pichard E. Vascular thrombosis and acute cytomegalovirus infection in im- munocompetent patients: report of 2 cases and literature review. Clin Infect Dis 2003; 36: e134-9.

[53] Kazory A, Ducloux D, Coaquette A, Manzoni P, Chalopin JM. Cytomegalovirus-associated venous thromboembolism in renal transplant recipients: a report of 7 cases. Transplantation 2004; 7: 597-9.

[54] de Boer OJ, van der Wal AC, Becker AE. Atherosclerosis, inflammation, and infection. J Pathol 2000; 190: 237-43.

[55] Streblow DN, Orloff SL, Nelson JA. Do pathogens accelerate atherosclerosis? J Nutr 2001; 131: 2798S-2804S.

[56] Armitage GC. Periodontal infections and cardiovascular disease-how strong is the association? Oral Dis 2000; 6: 335-50.

[57] Ricevuti G, Gritti D, Gasparetto C, Wiedermann CJ. Immune activation as effect modifier of atherogenesis in chronic infection. Int Rev Immunol 2002; 21: 27-31.

[58] Meurman JH, Sanz M, Janket SJ. Oral health, atherosclerosis, and cardiovascular disease. Crit Rev Oral Biol Med 2004; 15: 403-413.

[59] Corea F, Kwan J, Abbas MA. Predisposition to carotid atherosclerosis in ICARAS Dental Substudy. Stroke 2006; 38: 12.

[60] Naito M, Sakai E, Shi Y, et al. Porphyromonas gingivalis-induced platelet aggregation in plasma depends on Hgp44 adhesin but not Rgp proteinase. Mol Microbiol 2006; 59: 152-67.

[61] Mattila KJ, Pussinen PJ, Paju S. Dental infections and cardiovascular diseases: a review. J Periodontol 2005; 76(Suppl 11): 2085-8.

[62] Beck JD, Eke P, Lin D, et al. Associations between IgG antibody to oral organisms and carotid intima-medial thickness in communitydwelling adults. Atherosclerosis 2005; 183: 342-348.

[63] Anderson JL, Muhlestein JB, Carlquist J, et al. Randomized secondary prevention trial of azithromycin in patients with coronary artery disease and serological evidence for Chlamydia pneumoniae infection: the Azithromycin in Coronary Artery Disease: Elimination of Myocardial Infection with Chlamydia (ACADEMIC) study. Circulation 1999; 99: 1540-1547.

[64] Gurfinkel E, Bozovich G, Beck E, Testa E, Livellara B, Mautner B. Treatment with the antibiotic roxithromycin in patients with acute non-Q-wave coronary syndromes: the final report of the ROXIS Study. Eur Heart J 1999; 20: 121-127.

[65] Tiran A, Gruber HJ, Graier WF, Wagner AH, Van Leeuwen EB, Tiran B. Aspirin inhibits Chlamydia pneumoniae-induced nuclear factor-kappa B activation, cytokine expression, and bacterial development in human endothelial cells. Arterioscler Thromb Vasc Biol 2002; 22: 1075-80.

[66] Lecomte F, Benhamou D. [New macrolides] Rev Med Interne 1998; 19: 255-61.

[67] Uriarte SM, Molestina RE, Miller RD, et al. Effect of macrolide antibiotics on human endothelial cells activated by Chlamydia pneumoniae infection and tumor necrosis factor-alpha. J Infect Dis 2002; 185: 1631-6.

[68] Gurfinkel E. Link between intracellular pathogens and cardiovascular diseases. Clin Microbiol Infect 1998; 4(Suppl 4): S33-S36.

[69] Fong IW, Chiu B, Viira E, Jang D, Mahony JB. Influence of clarithromycin on early atherosclerotic lesions after Chlamydia pneumoniae infection in a rabbit model. Antimicrob Agents Chemother 2002; 46: 2321-6.

[70] Grau AJ, Marquardt L, Lichy C. The effect of infections and vaccinations on stroke risk. Expert Rev Neurother 2006; 6: 175-83.

[71] Pesonen E, Andsberg E, Ohlin H, et al. Dual role of infections as risk factors for coronary heart disease. Atherosclerosis 2007; 192: 370-5.

[72] Thorpe C, Edwards L, Snelgrove R, et al. Discovery of a vaccine antigen that protects mice from Chlamydia pneumoniae infection. Vaccine 2007; 25(12): 2252-60. 